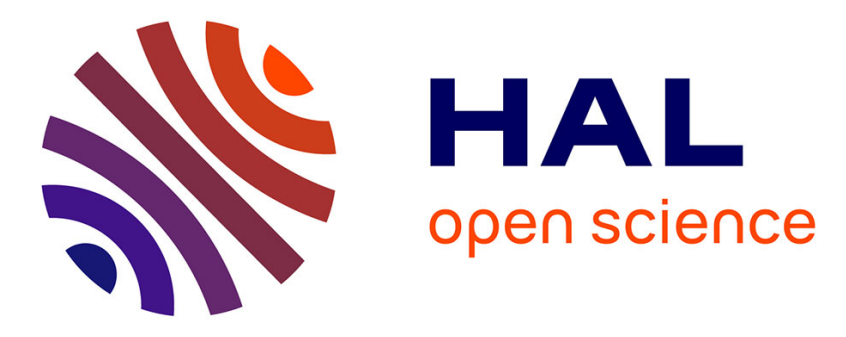

\title{
Welding and the risk of head and neck cancer: the ICARE study
}

Christine Barul, Mireille Matrat, Aviane Auguste, Julien Dugas, Loredana

Radoi, Gwenn Menvielle, Joëlle Févotte, Anne-Valérie Guizard, Isabelle

Stücker, Danièle Luce

\section{To cite this version:}

Christine Barul, Mireille Matrat, Aviane Auguste, Julien Dugas, Loredana Radoi, et al.. Welding and the risk of head and neck cancer: the ICARE study. Occupational and Environmental Medicine, 2020, 77 (5), pp.293-300. 10.1136/oemed-2019-106080 . hal-02453456

\section{HAL Id: hal-02453456 https://hal-univ-rennes1.archives-ouvertes.fr/hal-02453456}

Submitted on 23 Jan 2020

HAL is a multi-disciplinary open access archive for the deposit and dissemination of scientific research documents, whether they are published or not. The documents may come from teaching and research institutions in France or abroad, or from public or private research centers.
L'archive ouverte pluridisciplinaire HAL, est destinée au dépôt et à la diffusion de documents scientifiques de niveau recherche, publiés ou non, émanant des établissements d'enseignement et de recherche français ou étrangers, des laboratoires publics ou privés. 
Title: Welding and the risk of head and neck cancer: the ICARE Study.

Christine Barul ${ }^{1}$, Mireille Matrat ${ }^{2,3,4}$, Aviane Auguste ${ }^{1}$, Julien Dugas ${ }^{1}$, Loredana Radoï ${ }^{2,5}$, Gwenn Menvielle $^{6}$, Joelle Févotte ${ }^{7}$, Anne-Valérie Guizard ${ }^{8,9}$, Isabelle Stücker ${ }^{2}$, and Danièle Luce $^{1}$; ICARE study group.

\section{Affiliations:}

1. Univ Rennes, Inserm, EHESP, Irset (Institut de recherche en santé, environnement et travail) -UMR_S 1085, F-97100 Pointe-à-Pitre, France

2. CESP, Cancer and Environment team, INSERM U1018, Université Paris-Sud, Université Paris-Saclay, Villejuif, France

3. Faculty of medicine, Paris Est Créteil University, Créteil, France

4. Intercommunal hospital center, Service des Pathologies Professionnelles et de l'Environnement, Créteil, France

5. Faculty of dental surgery, University Paris Descartes, France

6. Sorbonne Université, Inserm, Institut Pierre Louis d'Epidémiologie et Santé Publique IPLESP, Department of social epidemiology, F75012, Paris ; France

7. Fonds d'Indemnisation des Victimes de l'Amiante, Bagnolet, France

8. Registre Général des Tumeurs du Calvados, Centre François Baclesse, Caen, France

9. ANTICIPE" U1086 INSERM-University of Caen Normandy, Centre François Baclesse, Caen, France.

\section{Authors' e-mail addresses:}

Christine Barul: christine.barul@iaf.inrs.ca

Mireille Matrat: mireille.matrat@inserm.fr

Aviane Auguste:aviane.auguste@inserm.fr

Julien Dugas: julien.dugas@inserm.fr

Loredana Radoï: loredana.radoi@inserm.fr

Gwenn Menvielle: gwenn.menvielle@inserm.fr

Joelle Févotte: joelle.fevotte@gmail.com

Anne-Valérie Guizard: av.guizard@baclesse.unicancer.fr

Isabelle Stücker: isabelle.stucker@inserm.fr

Danièle Luce: daniele.luce@inserm.fr

Corresponding author: Dr Danièle Luce

Address: INSERM U1085-IRSET, Faculté de Médecine, Campus de Fouillole, BP 145,

97154, Pointe-à-Pitre, France

E-mail: daniele.luce@inserm.fr 
Word Count: 238

Abstract:

Objective: to investigate the association between occupational exposure to welding and the risk of head and neck cancer in a large French population-based case-control study, the ICARE study. Methods: Analyses were restricted to men (2,703 controls and 1,588 cases of squamous-cell carcinoma of the oral cavity, oropharynx, hypopharynx and larynx. Welding activity and potential confounders were assessed by detailed questionnaires. Odds ratios (ORs) and confidence intervals $(95 \% \mathrm{Cl})$ were estimated by unconditional logistic regression, adjusted for age, area of residence, tobacco smoking, alcohol consumption, and occupational exposure to asbestos. Results: Welding was associated with an increased risk of head and neck cancer overall $(\mathrm{OR}=1.31,95 \% \mathrm{Cl} 1.03$ to 1.67$)$. The association was strongest for laryngeal cancer $(\mathrm{OR}=1.66,95 \% \mathrm{Cl} 1.15$ to 2.38$)$ and the risk increased with the cumulative duration ( $p$-trend $<0.01)$ and the weighted duration ( $p$-trend $<0.01$ ) of welding. A cumulative duration and a weighted duration of welding of more than 10 years were also associated with a significantly increased risk of oral cancer $(\mathrm{OR}=1.82,95 \% \mathrm{Cl} 1.09$ to 3.04 ; $\mathrm{OR}=2.10,95 \% \mathrm{Cl} 0.99$ to 4.45 , respectively). A long duration of arc welding was associated with laryngeal cancer, whereas a long duration of spot welding was associated with oral cancer. Welding was not associated with the risk of oropharyngeal and hypopharyngeal cancer.

Conclusion: Our findings suggest that welding and several welding-related tasks increase the risk of laryngeal cancer and to a lesser extent oral cancer.

Key terms: head and neck, epidemiology, occupational health, tumor, case-control study 


\section{Word Count: 3,497}

\section{Introduction}

Welding fumes have been classified as carcinogenic to humans by the International Agency for Research on Cancer (IARC) because of sufficient evidence for lung cancer [1]. These fumes contain several chemicals which vary, depending on the metal to be welded, its coating, or the welding process [2,3]. For example, concentrations of nickel compounds and hexavalent chromium, recognized carcinogens, are much higher in stainless steel than in mild-steel. On the other hand, mild-steel welding generates higher mass concentrations of particulate matter than stainless steel welding. Welding also involves co-exposures to coatings of the welded metal, chemicals used to clean the metal before welding, and asbestos, as part of the protective equipment or from the working environment [1].

Few studies have examined the association between welding and the risk of head and neck cancer. Most cohort studies of welders did not report on these cancers, or included a small number of cases, and did not control for tobacco and alcohol consumption, the main risk factors of head and neck cancer [4]. Case-control studies on welding are more informative, as confounding by smoking and alcohol has routinely been accounted for. Positive associations between head and neck cancer and welding were reported in some [512], but not all case-control studies [13-18]. However, the majority of these studies were based on a small number of exposed cases and did not account for the confounding effect of asbestos exposure, a known occupational risk factor of laryngeal cancer to which welders are commonly exposed. In addition, very few studies have examined the risk of head and neck cancer according to the duration of welding [5], the use of a specific welding process [6] or the type of metal welded [7], although these are major determinants of exposure.

Previously, in a large French population-based case-control study, the ICARE study, we found increased risks of head and neck cancer among men [19] and women [20] who had been employed as 'welders and flame-cutters'. However, the number of workers who perform welding may be ten times higher than the number of workers with the job title of welder $[1,21]$. 
Here, we aimed to investigate the association between head and neck cancer and welding as a job task, regardless of the job title. We examined several parameters of exposure and carefully took into account the main behavioural and occupational risk factors. 


\section{Methods}

\section{Study design}

We used data from a French multicenter population-based case-control study, the ICARE study (Investigation of occupational and environmental CAuses of REspiratory cancers study), conducted between 2001 and 2007 in ten geographical areas covered by a cancer registry. The detailed study design is available elsewhere [22]. Briefly, incident cases of head and neck cancer were collected from almost all healthcare establishments in each area in collaboration with cancer registries. Patients aged between 18 and 75 years, first diagnosed during the study period with a histologically confirmed primary cancer of the oral cavity, pharynx, or larynx fulfilled the eligibility criteria of the study. Controls were selected by incidence density sampling in the same geographical areas as the cases, with frequencymatching by gender and age. Additional stratification was performed to achieve an occupational class distribution in controls comparable to that of the general population of the same geographical areas. Participation rates were $80.6 \%$ for controls and $82.5 \%$ for cases [22].

The study was approved by the Institutional Review Board of the French National Institute of Health and Medical Research (IRB-Inserm, $\mathrm{n}^{\circ}$ 01-036) and the French Data Protection Authority (CNIL n 90120).

\section{Data collection}

Participants were interviewed face to face by trained interviewers with standardized questionnaires including sociodemographic characteristics, smoking and alcohol consumption history and detailed lifetime occupational history, covering all jobs held for at least one month. Participants who were severely ill or extremely tired $(11 \%$ of cases/ $2 \%$ of controls) were interviewed either in person or through a next-of-kin with a shorter version of the questionnaire, which mainly covered information on tobacco and alcohol consumption and occupational history. The international Standard Classification of Occupations (ISCO) and the French Nomenclature of Activities were used by trained coders to code occupations 
and branches of the industry, independently of the case-control status of the participants $[23,24]$.

A job-specific questionnaire on welding, brazing and flame cutting was given to participants for whom at least $5 \%$ of their working time was devoted to this task.

\section{Assessment of welding activity}

Welding was defined as having at least one job period as 'welder and flame-cutter' (coded 872 in ISCO code) and/or having declared a welding or flame-cutting activity in the general questionnaire that occupied at least $5 \%$ of the working time in at least one job of the occupational lifetime. Other participants were included in the 'no welding' category. Participants were interviewed with the specific questionnaire on welding, which contained detailed questions about the welding processes, the type of metals welded, the treatments (mechanical or chemical) used to clean the surface before welding and the duration and associated frequency of welding (as a percentage of working time) for each job period.

\section{Assessment of other occupational exposures}

Occupational exposure to asbestos was assessed through a specific job-exposure matrix accounting for exposure generated by the occupational tasks and the occupational environment [25]. Information on exposure to strong inorganic acids was obtained for each job from specific questions in the questionnaire.

\section{Study sample}

The present study was restricted to men, as only ten women ( 4 cases/ 6 controls) were welders [20] and seven others (only controls) were not but reported a welding activity of more than $5 \%$ of their working time. The study was also restricted to squamous cell carcinomas of the following cancer sites, according to the codes of the International Classification of Diseases for Oncology, third edition (ICD-O-3): oral cavity (C00.3-9; C02.0-3; C03.0-1; C03.9, C04.0-1; C04.8-9; C05.0; C06.0-2; C06.8-9), oropharynx (C01.9; C02.4; C05.1-2; C09.0-1; C09.8-9; C10.0-4; C10.8-9), hypopharynx (C12.9; C13.0-2; C13.8; C13.9), oral cavity or pharynx not otherwise specified or overlapping (C02.8, C02.9, C05.8, C05.9, C14.0, 
C14.2, C14.8), and larynx (C32.0-3; C32.8-9). Participants with missing data concerning welding were excluded (269 cases and 77 controls).

Overall, 1,588 male cases of head and neck cancer (301 with oral cancer, 472 with oropharyngeal cancer, 316 with hypopharyngeal cancer, 107 with oral or pharyngeal cancer not otherwise specified or overlapping and 392 with laryngeal cancer) and 2,703 male controls were included in the study.

\section{Statistical analysis}

Odds ratios (ORs) and confidence intervals $(95 \% \mathrm{Cl})$ were estimated using multivariable unconditional logistic regression, modelling the association between welding and the overall risk of head and neck cancer and by specific anatomical sites (oral cavity, oropharynx, hypopharynx, and larynx). Analyses were adjusted for age at interview, area of residence, alcohol consumption (glass/day), smoking status (never, former: time since stopping smoking $>2$ years at the time of the interview, current), daily amount of tobacco consumption (gram/day), duration of tobacco smoking (years), and a cumulative index of occupational exposure to asbestos. To allow for non-linear associations, continuous variables were included in the models as restricted cubic splines, with three knots for age and alcohol consumption and four knots for amount and duration of tobacco smoking and asbestos exposure. For laryngeal cancer, additional adjustment for self-reported occupational exposure to strong inorganic acids (sulfuric and/or hydrochloric acids) was also performed.

No welding was the reference category for all analyses. We examined the associations between the risk of head and neck cancer and the total cumulative duration of welding. In order to better reflect the real exposure, we also calculated a weighted duration over all jobs as follows:

$W D=\Sigma\left(D_{i} \times F_{i}\right)$ 
Where $D_{i}$ is the duration of the job $i$ and $F_{i}$ the frequency of welding in the job $i$, expressed as a proportion of the working time. These continuous exposure variables were categorized according to approximate percentiles on exposed controls' distributions (median for duration of welding; quartiles for weighted duration of welding). Tests for trend were performed using the median value for each category as an ordinal variable.

Finally, we estimated the risk of head and neck cancer according to the most common welding processes, the type of metals welded and the use of chemical or mechanical treatments to clean the surface before welding. All analyses were performed using SAS (version 9.4; SAS Institute, Cary, North Carolina). 


\section{Results}

Overall, 242 cases (16\%) and 299 controls (11\%) had welded in their working life. Among them, 32\% (100 cases and 71 controls) had ever worked as "welders and flame cutters" (ISCO code 8.72 ) and 68\% (142 cases and 228 controls) had never been employed in this occupational group, but had performed welding in other jobs. These other jobs were mainly sheet-metal workers (17\%, ISCO code 8.73 ), plumbers and pipe fitters (16\%, ISCO code 8.71) machinery fitters, machine assemblers and precision instrument makers (18\%, ISCO code 8.4$)$ and blacksmiths, toolmakers and machine-tool operators (11\%, ISCO code 8.3).

The associations between welding and the risk of head and neck cancer are presented in Table 1. Welding was associated with an increased risk of head and neck cancer $(O R=$ $1.31,95 \% \mathrm{Cl} 1.03$ to 1.67$)$ and the risk increased with the cumulative duration ( $\mathrm{p}$-trend=0.01) and the weighted duration ( $\mathrm{p}$-trend $=0.05$ ) of welding. The association was strongest for laryngeal cancer $(\mathrm{OR}=1.66,95 \% \mathrm{Cl} 1.15$ to 2.38$)$, particularly for welding more than 10 years, either considering the cumulative duration $(\mathrm{OR}=1.87,95 \% \mathrm{Cl} 1.20$ to 2.94$)$ or the weighted duration of welding $(\mathrm{OR}=2.42,95 \% \mathrm{Cl} 1.25$ to 4.69$)$, with significant increasing trends for both metrics $(p<0.01)$. Welding was not associated with oral cancer but an increased risk was found for the longest cumulative duration ( $\mathrm{OR}=1.82 ; 95 \% 1.09$ to 3.04 ) and weighted duration $(\mathrm{OR}=2.10,95 \% 0.99$ to 4.45$)$, with borderline significant trends $(p=0.07, p=0.05$, respectively). We found no association between welding and the risk of oropharyngeal or hypopharyngeal cancer. 
Table 1. Risk of head and neck cancer associated with welding.

\begin{tabular}{|c|c|c|c|c|c|c|c|c|c|c|c|c|c|c|c|c|}
\hline & \multirow{2}{*}{$\begin{array}{c}\text { Controls } \\
n\end{array}$} & \multicolumn{3}{|c|}{ Cases } & \multicolumn{3}{|c|}{ Oral cavity } & \multicolumn{3}{|c|}{ Oropharynx } & \multicolumn{3}{|c|}{ Hypopharynx } & \multicolumn{3}{|c|}{ Larynx } \\
\hline & & $\mathbf{n}$ & $\mathrm{OR}^{*}$ & $95 \% \mathrm{Cl}$ & $\mathbf{n}$ & $\mathrm{OR}^{*}$ & $95 \% \mathrm{Cl}$ & $\mathbf{n}$ & $\mathrm{OR}^{*}$ & $95 \% \mathrm{Cl}$ & $\mathbf{n}$ & $\mathrm{OR}^{*}$ & $95 \% \mathrm{Cl}$ & $\mathbf{n}$ & $\mathrm{OR}^{*}$ & $95 \% \mathrm{Cl}$ \\
\hline No welding ${ }^{\dagger}$ & 2316 & 1267 & 1 & Ref & 244 & 1 & Ref & 380 & 1 & Ref & 243 & 1 & Ref & 315 & 1 & Ref \\
\hline Welding & 299 & 242 & 1.31 & 1.03 to 1.67 & 43 & 1.29 & 0.85 to 1.97 & 68 & 0.96 & 0.67 to 1.38 & 51 & 1.37 & 0.91 to 2.06 & 62 & 1.66 & 1.15 to 2.38 \\
\hline \multicolumn{17}{|c|}{ Cumulative duration of welding (years) } \\
\hline$\leq 10$ & 136 & 90 & 1.07 & 0.75 to 1.53 & 13 & 0.75 & 0.38 to 1.49 & 29 & 0.81 & 0.47 to 1.37 & 20 & 1.30 & 0.72 to 2.36 & 22 & 1.39 & 0.81 to 2.39 \\
\hline$>10$ & 163 & 150 & 1.50 & 1.10 to 2.04 & 30 & 1.82 & 1.09 to 3.04 & 39 & 1.04 & 0.70 to 1.75 & 29 & 1.29 & 0.76 to 2.18 & 40 & 1.87 & 1.20 to 2.94 \\
\hline $\mathrm{p}$-trend & & & 0.01 & & & 0.07 & & & 0.91 & & & 0.25 & & & $<0.01$ & \\
\hline \multicolumn{17}{|c|}{ Weighted duration of welding (years) } \\
\hline$\leq 1$ & 65 & 31 & 1.03 & 0.61 to 1.75 & 5 & 0.87 & 0.31 to 2.46 & 10 & 0.86 & 0.39 to 1.90 & 7 & 1.21 & 0.49 to 2.99 & 6 & 1.06 & 0.43 to 2.64 \\
\hline [1 to 5[ & 88 & 60 & 0.95 & 0.61 to 1.48 & 10 & 0.86 & 0.39 to 1.90 & 21 & 0.87 & 0.46 to 1.64 & 10 & 0.69 & 0.29 to 1.63 & 13 & 1.00 & 0.50 to 1.99 \\
\hline [5 to 10$]$ & 25 & 28 & 1.63 & 0.78 to 3.40 & 7 & 2.50 & 0.82 to 7.66 & 6 & 1.04 & 0.35 to 3.15 & 5 & 1.49 & 0.45 to 4.95 & 8 & 2.53 & 0.98 to 6.51 \\
\hline$>10$ & 47 & 65 & 1.61 & 0.99 to 2.62 & 13 & 2.10 & 0.99 to 4.45 & 14 & 0.90 & 0.44 to 1.82 & 16 & 1.58 & 0.78 to 3.23 & 19 & 2.42 & 1.25 to 4.69 \\
\hline $\mathrm{p}$-trend & & & 0.05 & & & 0.05 & & & 0.67 & & & 0.30 & & & $<0.01$ & \\
\hline
\end{tabular}

Abbreviations: $\mathrm{y}=$ years, $\mathrm{OR}=$ odds-ratio, $\mathrm{Cl}=$ confidence interval, Ca: cases, Co: controls

"OR adjusted for age at interview, area of residence, alcohol consumption, smoking status, frequency and duration of smoking, and exposure to asbestos.

†Reference category contains participants who had never welded and those who had welded less than $5 \%$ of their working time in all their jobs involving welding. 
We explored the role of the most common welding processes and the corresponding weighted durations (Table 2). We observed a significant increased risk of head and neck cancer related to having ever performed arc welding $(\mathrm{OR}=1.36,95 \% \mathrm{Cl} 1.02$ to 1.81$)$ and a borderline significant OR of 1.58 linked to a long-term weighted duration using this process. In analyses by subsite, an increased risk of oral cancer emerged in workers with the longest weighted duration of spot welding $(\mathrm{OR}=3.47,95 \% \mathrm{Cl} 1.27$ to 9.48). An increased risk of laryngeal cancer appeared in workers who had ever gas welded $(\mathrm{OR}=1.54,95 \% \mathrm{Cl} 1.01$ to 2.34) and in those with the longest weighted duration of arc welding $(\mathrm{OR}=2.42,95 \% \mathrm{Cl} 1.27$ to 4.60). No other significant association was found. It should be noted that analyses by subsite according to weighted duration were based on a small number of exposed cases. 
Table 2. Risk of head and neck cancer associated with the ever use and the weighted duration of a welding process

\begin{tabular}{|c|c|c|c|c|c|c|c|c|c|c|c|c|c|c|c|c|}
\hline & \multirow{2}{*}{$\frac{\text { Controls }}{n}$} & \multicolumn{3}{|c|}{ Cases } & \multicolumn{3}{|c|}{ Oral cavity } & \multicolumn{3}{|c|}{ Oropharynx } & \multicolumn{3}{|c|}{ Hypopharynx } & \multicolumn{3}{|c|}{ Larynx } \\
\hline & & $\mathbf{n}$ & $\mathrm{OR}^{*}$ & $95 \% \mathrm{Cl}$ & $\mathbf{n}$ & OR $^{*}$ & $95 \% \mathrm{Cl}$ & $\mathbf{n}$ & OR $^{*}$ & $95 \% \mathrm{Cl}$ & $\mathbf{n}$ & $\mathrm{OR}^{*}$ & $95 \% \mathrm{Cl}$ & $\mathbf{n}$ & $\mathrm{OR}^{*}$ & $95 \% \mathrm{Cl}$ \\
\hline No welding ${ }^{\dagger}$ & 2316 & 1267 & 1 & Ref & 244 & 1 & Ref & 380 & 1 & Ref & 243 & 1 & Ref & 315 & 1 & Ref \\
\hline \multicolumn{17}{|c|}{ Ever use of a welding process ${ }^{¥}$} \\
\hline Soldering & 117 & 89 & 1.22 & 0.84 to 1.77 & 16 & 1.26 & 0.66 to 2.38 & 21 & 0.83 & 0.47 to 1.47 & 19 & 1.20 & 0.64 to 2.27 & 26 & 1.54 & 0.90 to 2.62 \\
\hline Brazing & 95 & 53 & 0.95 & 0.61 to 1.79 & 11 & 0.88 & 0.42 to 1.88 & 16 & 0.79 & 0.41 to 1.51 & 10 & 0.79 & 0.35 to 1.76 & 13 & 1.03 & 0.52 to 2.04 \\
\hline Gas welding & 219 & 173 & 1.26 & 0.95 to 1.67 & 35 & 1.40 & 0.87 to 2.25 & 51 & 1.01 & 0.67 to 1.52 & 30 & 1.00 & 0.61 to 1.66 & 45 & 1.54 & 1.01 to 2.34 \\
\hline Arc welding & 199 & 169 & 1.36 & 1.02 to 1.81 & 34 & 1.58 & 0.97 to 2.56 & 49 & 1.15 & 0.76 to 1.77 & 31 & 1.28 & 0.78 to 2.12 & 40 & 1.53 & 0.98 to 2.37 \\
\hline Spot welding & 94 & 71 & 1.27 & 0.84 to 1.92 & 15 & 1.63 & 0.82 to 3.24 & 17 & 0.77 & 0.41 to 1.47 & 11 & 0.90 & 0.42 to 1.92 & 19 & 1.48 & 0.80 to 2.72 \\
\hline \multicolumn{17}{|c|}{ Weighted duration by welding process (years) } \\
\hline \multicolumn{17}{|l|}{ Soldering } \\
\hline ] 0 to 0.30$]$ & 33 & 13 & 0.60 & 0.27 to 1.32 & 2 & 0.71 & 0.16 to 3.22 & 4 & 0.51 & 0.15 to 1.73 & 2 & 0.34 & 0.07 to 1.74 & 4 & 0.92 & 0.28 to 3.00 \\
\hline$>0.30$ & 34 & 28 & 1.06 & 0.54 to 2.06 & 5 & 1.04 & 0.34 to 3.14 & 6 & 0.77 & 0.29 to 2.07 & 8 & 1.07 & 0.36 to 3.12 & 6 & 1.12 & 0.42 to 3.01 \\
\hline \multicolumn{17}{|l|}{ Brazing } \\
\hline ] 0 to 0.61 ] & 27 & 9 & 0.57 & 0.22 to 1.45 & 1 & 0.28 & 0.03 to 2.33 & 4 & 0.59 & 0.17 to 2.12 & 1 & 0.19 & 0.02 to 1.60 & 2 & 0.50 & 0.10 to 2.43 \\
\hline$>0.61$ & 26 & 16 & 1.15 & 0.50 to 2.67 & 3 & 1.14 & 0.30 to 4.36 & 6 & 1.08 & 0.35 to 3.28 & 5 & 1.53 & 0.41 to 5.78 & 2 & 0.52 & 0.10 to 2.59 \\
\hline \multicolumn{17}{|l|}{ Gas welding } \\
\hline ] 0 to 0.90 ] & 72 & 39 & 0.97 & 0.58 to 1.60 & 5 & 0.49 & 0.16 to 1.44 & 12 & 0.70 & 0.32 to 1.51 & 8 & 0.79 & 0.32 to 1.95 & 13 & 1.65 & 0.82 to 3.33 \\
\hline$>0.90$ & 67 & 65 & 1.41 & 0.89 to 2.23 & 13 & 1.89 & 0.91 to 3.88 & 16 & 0.87 & 0.44 to 1.73 & 14 & 1.17 & 0.55 to 2.50 & 16 & 1.46 & 0.74 to 2.91 \\
\hline \multicolumn{17}{|l|}{ Arc welding } \\
\hline ] 0 to 1.70 ] & 57 & 38 & 1.31 & 0.76 to 2.24 & 8 & 1.14 & 0.46 to 2.85 & 4 & 1.50 & 0.71 to 3.17 & 7 & 0.75 & 0.26 to 2.12 & 8 & 1.33 & 0.56 to 3.13 \\
\hline$>1.70$ & 56 & 69 & 1.58 & 0.99 to 2.51 & 8 & 1.35 & 0.56 to 3.25 & 7 & 1.05 & 0.55 to 2.03 & 16 & 1.80 & 0.89 to 3.64 & 20 & 2.42 & 1.27 to 4.60 \\
\hline \multicolumn{17}{|l|}{ Spot welding } \\
\hline ] 0 to 0.58 ] & 27 & 20 & 1.14 & 0.53 to 2.48 & 2 & 0.45 & 0.09 to 2.33 & 6 & 0.93 & 0.29 to 2.91 & 4 & 0.71 & 0.19 to 2.67 & 4 & 1.04 & 0.30 to 3.68 \\
\hline$>0.58$ & 27 & 21 & 1.32 & 0.65 to 2.70 & 7 & 3.47 & 1.27 to 9.48 & 3 & 0.42 & 0.11 to 1.64 & 5 & 1.54 & 0.50 to 4.69 & 4 & 1.33 & 0.42 to 4.22 \\
\hline
\end{tabular}

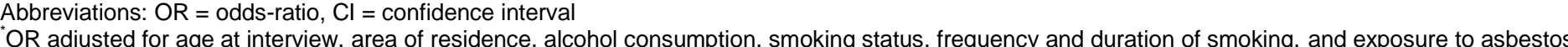

†Reference category contains participants who had never welded and those who had welded less than $5 \%$ of their working time in all their jobs involving welding.

¥Welding processes were not mutually exclusive. 
We also investigated the role of the type of metal welded (Table 3). Having ever welded iron was associated with an increased risk of laryngeal cancer (OR=1.83, 95\% $\mathrm{Cl} 1.01$ to 3.34$)$. There was no other association between the ever use of a specific metal and the risk of head and neck cancer overall and by subsite, although for most metals the number of exposed cases by subsite was small. 
Table 3. Risk of head and neck cancers associated with the type of welded metal

\begin{tabular}{|c|c|c|c|c|c|c|c|c|c|c|c|c|c|c|c|c|}
\hline & \multirow{2}{*}{$\begin{array}{c}\text { Controls } \\
n\end{array}$} & \multicolumn{3}{|c|}{ Cases } & \multicolumn{3}{|c|}{ Oral cavity } & \multicolumn{3}{|c|}{ Oropharynx } & \multicolumn{3}{|c|}{ Hypopharynx } & \multicolumn{3}{|c|}{ Larynx } \\
\hline & & $\mathbf{n}$ & OR $^{*}$ & $95 \% \mathrm{Cl}$ & $\mathbf{n}$ & $O^{*}$ & $95 \% \mathrm{Cl}$ & $\mathbf{n}$ & OR $^{*}$ & $95 \% \mathrm{Cl}$ & $\mathbf{n}$ & OR $^{*}$ & $95 \% \mathrm{Cl}$ & $\mathbf{n}$ & $\mathrm{OR}^{*}$ & $95 \% \mathrm{Cl}$ \\
\hline No welding $†$ & 2316 & 1267 & 1 & Ref & 244 & 1 & Ref & 380 & 1 & Ref & 243 & 1 & Ref & 315 & 1 & Ref \\
\hline \multicolumn{17}{|l|}{ Ever welded metal } \\
\hline Aluminium & 22 & 24 & 1.36 & 0.63 to 2.95 & 5 & 2.86 & 0.83 to 9.88 & 9 & 1.55 & 0.57 to 4.22 & 3 & 0.79 & 0.18 to 3.44 & 6 & 1.71 & 0.55 to 5.28 \\
\hline Lead & 19 & 21 & 1.20 & 0.53 to 2.73 & 5 & 1.39 & 0.43 to 4.52 & 5 & 0.79 & 0.23 to 2.70 & 4 & 1.28 & 0.32 to 5.17 & 5 & 1.10 & 0.33 to 3.70 \\
\hline Cast iron & 22 & 20 & 0.93 & 0.42 to 2.06 & 2 & 0.59 & 0.12 to 2.90 & 7 & 0.85 & 0.29 to 2.49 & 5 & 1.10 & 0.32 to 3.76 & 5 & 0.95 & 0.29 to 3.04 \\
\hline Copper & 32 & 48 & 1.74 & 0.97 to 3.15 & 8 & 1.63 & 0.63 to 4.23 & 15 & 1.57 & 0.72 to 3.42 & 9 & 1.01 & 0.36 to 2.80 & 11 & 2.03 & 0.89 to 4.63 \\
\hline Galvanized metal & 39 & 41 & 1.00 & 0.55 to 1.84 & 4 & 0.72 & 0.22 to 2.42 & 16 & 1.22 & 0.57 to 2.61 & 8 & 0.82 & 0.30 to 2.23 & 8 & 1.03 & 0.40 to 2.64 \\
\hline Stainless steel & 31 & 38 & 1.58 & 0.84 to 2.99 & 5 & 1.47 & 0.46 to 4.73 & 14 & 1.71 & 0.76 to 3.86 & 7 & 1.42 & 0.50 to 4.03 & 8 & 1.76 & 0.68 to 4.56 \\
\hline Mild steel & 86 & 63 & 0.98 & 0.64 to 1.52 & 10 & 0.88 & 0.40 to 1.94 & 20 & 0.98 & 0.53 to 1.80 & 11 & 0.69 & 0.32 to 1.50 & 17 & 1.29 & 0.68 to 2.47 \\
\hline Iron & 79 & 78 & 1.39 & 0.91 to 2.11 & 10 & 0.98 & 0.43 to 2.25 & 22 & 1.06 & 0.58 to 1.93 & 20 & 1.51 & 0.79 to 2.91 & 21 & 1.83 & 1.01 to 3.34 \\
\hline
\end{tabular}

Abbreviations: $\mathrm{OR}=$ odds-ratio, $\mathrm{Cl}=$ confidence interval

"OR adjusted for age at interview, area of residence, alcohol consumption, smoking status, frequency and duration of smoking, and exposure to asbestos

tReference category contains participants who had never welded and those who had welded less than $5 \%$ of their working time in all their jobs involving welding. 
We examined the risk of head and neck cancer according to the treatment used to clean the surface before welding (Table 4). Cleaning exclusively with a mechanical treatment was associated with a higher risk of head and neck cancer ( $\mathrm{OR}=1.42,95 \% \mathrm{Cl} 1.06$ to 1.92) and of laryngeal cancer $(\mathrm{OR}=1.66,95 \% \mathrm{Cl} 1.11 ; 2.50)$. The ever use of chemical treatments was not associated with the risk of head and neck cancer. However, when chemicals were analyzed separately, having ever used acid was associated with an increased risk of head and neck cancer $(\mathrm{OR}=2.69,95 \% \mathrm{Cl} 1.19 ; 6.09)$, particularly oral $(\mathrm{OR}=4.42,95 \% \mathrm{Cl} 1.53$; 12.72) and laryngeal cancer $(\mathrm{OR}=4.53,95 \% \mathrm{Cl} 1.73 ; 11.89)$. No association was found for the other chemical treatments. 
Table 4. Risk of head and neck cancer associated with the type of treatment used before welding

\begin{tabular}{|c|c|c|c|c|c|c|c|c|c|c|c|c|c|c|c|c|}
\hline & \multirow{2}{*}{$\frac{\text { Controls }}{n}$} & \multicolumn{3}{|c|}{ Cases } & \multicolumn{3}{|c|}{ Oral cavity } & \multicolumn{3}{|c|}{ Oropharynx } & \multicolumn{3}{|c|}{ Hypopharynx } & \multicolumn{3}{|c|}{ Larynx } \\
\hline & & $\mathbf{n}$ & $\mathrm{OR}^{*}$ & $95 \% \mathrm{Cl}$ & $\mathbf{n}$ & OR $^{*}$ & $95 \% \mathrm{Cl}$ & $\mathbf{n}$ & OR* & $95 \% \mathrm{Cl}$ & $\mathbf{n}$ & $\mathrm{OR}^{*}$ & $95 \% \mathrm{Cl}$ & $\mathbf{n}$ & $\mathrm{OR}^{*}$ & $95 \% \mathrm{Cl}$ \\
\hline No welding & 2316 & 1267 & 1 & Ref & 244 & 1 & Ref & 380 & 1 & Ref & 243 & 1 & Ref & 315 & 1 & Ref \\
\hline $\begin{array}{l}\text { Exclusive use of } \\
\text { mechanical treatments (never } \\
\text { use of chemicals) }\end{array}$ & 176 & 160 & 1.42 & 1.06 to 1.92 & 30 & 1.46 & 0.92 to 2.32 & 43 & 1.22 & 0.81 to 1.83 & 33 & 1.34 & 0.85 to 2.12 & 42 & 1.66 & 1.11 to 2.50 \\
\hline Ever used of chemicals & 122 & 82 & 1.15 & 0.79 to 1.67 & 13 & 1.01 & 0.53 to 1.93 & 25 & 1.09 & 0.65 to 1.81 & 18 & 1.20 & 0.67 to 2.14 & 20 & 1.22 & 0.70 to 2.10 \\
\hline \multicolumn{17}{|l|}{ Type of chemicals } \\
\hline Paint stripper & 32 & 24 & 1.75 & 0.83 to 3.69 & 4 & 1.80 & 0.55 to 5.89 & 6 & 1.32 & 0.47 to 3.71 & 4 & 1.43 & 0.43 to 4.71 & 7 & 2.13 & 0.80 to 5.64 \\
\hline Trichloroethylene & 56 & 46 & 1.39 & 0.82 to 2.35 & 8 & 1.31 & 0.57 to 3.04 & 13 & 1.25 & 0.62 to 2.54 & 10 & 1.42 & 0.65 to 3.12 & 11 & 1.43 & 0.68 to 3.02 \\
\hline Gasoline & 28 & 18 & 0.94 & 0.44 to 2.03 & 3 & 0.81 & 0.22 to 2.99 & 6 & 0.99 & 0.36 to 2.74 & 2 & 0.52 & 0.11 to 2.39 & 6 & 1.34 & 0.49 to 3.66 \\
\hline White spirits & 28 & 25 & 1.67 & 0.82 to 3.40 & 6 & 2.34 & 0.85 to 6.47 & 6 & 1.22 & 0.45 to 3.33 & 5 & 1.61 & 0.54 to 4.78 & 5 & 1.45 & 0.50 to 4.21 \\
\hline Acid & 16 & 26 & 2.69 & 1.19 to 6.09 & 7 & 4.42 & 1.53 to 12.72 & 3 & 0.91 & 0.24 to 3.52 & 4 & 1.92 & 0.55 to 6.66 & 10 & 4.53 & 1.73 to 11.89 \\
\hline
\end{tabular}

Abbreviations: OR = odds-ratio, $\mathrm{Cl}=$ confidence interval

†Reference category contains participants who had never welded and those who had welded less than $5 \%$ of their working time in all their jobs involving welding. 
As only seven participants (all cases) had data reported from next-of-kin, only marginal changes were found in sensitivity analyses removing those participants (data not shown). Finally, we investigated the role of welding in laryngeal cancer risk by additionally accounting for occupational exposure to strong inorganic acids. No substantial change was found in risk estimates (Supplementary Table S1). An increased risk of laryngeal cancer persisted in association with welding $(\mathrm{OR}=1.67,95 \% \mathrm{Cl} 1.16$ to 2.41$)$, and the risk increased with the cumulative duration ( $p$-trend $<0.01)$ and the weighted duration of exposure ( $p$-trend $<0.01$ ). A long-term duration of arc welding remained associated with an elevated risk of laryngeal cancer $(\mathrm{OR}=2.41,95 \% \mathrm{Cl} 1.27$ to 4.59$)$. 


\section{Discussion}

This study aimed to investigate the association between welding and the risk of head and neck cancer in men.

Here, welding was associated with an increased risk of head and neck cancer. The association was strongest for laryngeal cancer, with significant trends with duration. The increased risk of laryngeal cancer was particularly related to arc welding, welding iron, using exclusively mechanical treatments to clean metals before welding and cleaning with acid. Increased risk of oral cancer was associated with a long duration of welding, with the use of acid before welding and with spot welding. Welding was not associated with the occurrence of oropharyngeal and hypopharyngeal cancer.

Findings have been sparse in cohort studies that investigated head and neck cancer by anatomical site. Only one cohort study considered oral and pharyngeal cancer together and reported a SIR of 1.60 of borderline significance in welders (18 exposed cases). Several cohort studies have reported an elevated risk of laryngeal cancer for welders overall $[26,27]$ or specifically for gas welders [28], whereas others did not find any association [29-32]. These studies did not consider the confounding effects of smoking, alcohol consumption or occupational exposure to asbestos and strong inorganic acids, all known risk factors for laryngeal cancer.

Most case-control studies used the job title of "welder" as a proxy for exposure to welding fumes [8-13,15-19], whereas a few focused on exposure to welding fumes [5-7]. Some of the studies using the job title of "welder" reported elevated ORs for oral cancer [8], oral and pharyngeal cancers combined [10], oropharyngeal and hypopharyngeal combined [12], hypopharyngeal and laryngeal cancers combined [11] and laryngeal cancer [9,12], whereas others did not find any increased risk [13-18]. The largest one, a pooled analysis of 12 case-control studies (including $25 \%$ of subjects from the ICARE study), based on 475 welders and flame-cutters (256 cases/219 controls), reported higher risks of head and neck 
cancer $(\mathrm{OR}=1.51,95 \% \mathrm{Cl} 1.20$ to 1.90$)$, oropharyngeal and hypopharyngeal cancer combined $(\mathrm{OR}=1.42,95 \% \mathrm{Cl} 1.01$ to 1.99$)$ and laryngeal cancer $(\mathrm{OR}=1.52,95 \% \mathrm{Cl} 1.14$ to 2.02) [12]. An increased risk of head and neck cancer ( $\mathrm{OR}=1.9,95 \% \mathrm{Cl} 1.3$ to 2.3$)$, including oral $(\mathrm{OR}=1.9,95 \% \mathrm{Cl} 1.1$ to 3.3$)$, hypopharyngeal $(\mathrm{OR}=2.1,95 \% \mathrm{Cl} 1.2$ to 3.6$)$ and laryngeal cancer (OR=2.4, $95 \% \mathrm{Cl} 1.5$ to 4.0$)$ was also previously reported in male welders and flame cutters in the ICARE study [19]. In the present study risk estimates associated with welding were weaker, because men employed as welders and flame-cutters had on average a longer weighted duration of welding (12 years \pm 12 ) than men who reported welding in other jobs (5 years \pm 7 ). In addition, adjustment for asbestos exposure in our study led to a decrease in ORs.

Three case-control studies reported on the association between welding fumes and head and neck cancer. In a Swedish one, no increased risk of oral cancer was found associated with exposure to welding fumes, whereas borderline significantly elevated ORs were reported for pharyngeal and laryngeal cancers [5]. A borderline significantly OR was also reported for laryngeal cancer in a study from Denmark [7]. Inversely, no increased risk of hypopharyngeal and laryngeal cancer was found to be associated with welding fumes in a European multicenter study [6].

In summary, the available evidence is the strongest for laryngeal cancer, results are inconsistent for oral and hypopharyngeal cancer, and no association has been reported for oropharyngeal cancer. All case-control studies controlled for possible confounding effects of tobacco and alcohol consumption, but our study is the first to also adjust for occupational exposure to asbestos and to strong inorganic acids.

To date, only one study examined ever exposure to arc and gas welding fumes and reported ORs below 1 for laryngeal cancer. In this study, tobacco and alcohol consumption were controlled for in the analyses and asbestos and strong inorganic acids exposures were not associated with laryngeal cancer [6]. Here, we found an increased risk of laryngeal 
cancer associated with the longest weighted durations of arc welding with an indication of a dose-response relationship. The evidence was less clear for gas welding as there was no suggestion of an increasing trend in risk with weighted duration. Our study is the first to provide such detailed results.

With respect to the welded metals, a previous study reported a non-significant OR of 1.30 for laryngeal cancer associated with stainless steel welding. This result concurs with our findings, although exposure to asbestos was not taken into account [7]. We found a moderate increased risk of laryngeal cancer linked to having welded iron. This is the first investigation of this association. Further studies focusing on the role of metals used in welding in the occurrence of head and neck cancer are needed.

Using acid to prepare metal for welding was associated with an increased risk of laryngeal cancer We did not have information on the type of acid. Exposure to strong inorganic acid mists is a known risk factor for laryngeal cancer [33]. We also observed an increased risk of oral cancer in these workers.

Cleaning exclusively with mechanical treatments was associated with a higher risk of laryngeal cancer. Mechanical treatments including brushing, grinding, sand blasting or shot blasting are indicated when coatings have to be removed from the metals. Welders who used mechanical treatments are likely to have been exposed to higher levels of metal dust, paint dust and rust particles. The role of the treatment used to clean metals before welding has never been examined in the occurrence of head and neck cancer before.

The use of respiratory protection equipment may reduce the level of exposure to welding fumes but was reported by only $7 \%$ (11 controls/7 cases) of the exposed participants. Respirator use was reported as plain text in an open question and was not systematically collected, which limited further investigation of this topic.

The main limitation of our study was our inability to isolate the role of specific welding processes, metals and methods of treating the surface to be welded, because few 
participants used an exclusive welding process, metal or treatment before welding. In addition, sub-group analyses by cancer site were generally based on a small number of cases. Detailed welding activity was self-reported that could result in inflated risk estimates due to differential recall bias. However, this is likely not a major limitation here. Welding is not commonly perceived to be associated with head and neck cancer and the study was presented to participants as a study investigating 'health and environment'. Therefore, any exposure misclassification may rather be non-differential, which may have bias our estimates towards the null and underestimate the true effect of welding.

Information on human papillomavirus infection (HPV), a risk factor for oropharyngeal cancer, was not available. However, HPV infection is unlikely to be associated with welding. The prevalence of head and neck cancer caused by HPV infection was low in men during the study period [34], decreasing the probability of a major confounding bias in our analyses.

In addition to the many aspects of welding activity that we could investigate through our detailed questionnaire, several strengths reinforce the robustness of our study. The participation rate was good for cases and controls. Cases included in the ICARE study were incident cases with a distribution by age and cancer site similar to that observed in France [35]. Controls were randomly selected, conditional on age, from the same regions as the cases through incidence density sampling. A large number of participants were included in the study, providing sufficient statistical power to detect moderate associations and to investigate head and neck cancers overall and by anatomical subsite. Besides welders, we identified workers who used the technique in other jobs. Moreover, we took precautions to minimize confounding bias by considering major confounders, including tobacco and alcohol consumption and occupational exposure to asbestos and acid.

The evidence for the carcinogenicity of welding fumes for head and neck cancer is limited, mainly because of an insufficient number of studies investigating the association and inconsistent findings in epidemiological studies. No specific biological mechanism has yet 
been identified. Inhalation is the main route of exposure to welding fumes, directly exposing the epithelium of the upper respiratory tract to many induced particles. There is strong evidence that welding fumes induce inflammation and immunosuppression [1]. These mechanisms, involved in lung carcinogenicity of welding fumes, could be relevant for other parts of the respiratory tract.

\section{Conclusion:}

This study provides evidence that welding and several welding-related tasks increase the risk of laryngeal cancer, and to a lesser extent oral cancer. 


\section{Acknowledgements}

Members of ICARE Study Group: Anne-Valérie Guizard (Registre des cancers du Calvados, France); Arlette Danzon, Anne-Sophie Woronoff (Registre des cancers du Doubs, France); Michel Velten (Registre des cancers du Bas-Rhin, France); Antoine Buemi, Émilie Marrer (Registre des cancers du Haut-Rhin, France); Brigitte Trétarre (Registre des cancers de l'Hérault, France); Marc Colonna, Patricia Delafosse (Registre des cancers de l'Isère, France); Paolo Bercelli, Florence Molinié (Registre des cancers de Loire-Atlantique-Vendée, France); Simona Bara (Registre des cancers de la Manche, France); Bénédicte LapotreLedoux, Nicole Raverdy (Registre des cancers de la Somme, France); Sylvie Cénée, Oumar Gaye, Florence Guida, Farida Lamkarkach, Loredana Radoï, Marie Sanchez, Isabelle Stücker (INSERM, Centre for research in Epidemiology and Population Health (CESP), U1018, Environmental Epidemiology of Cancer Team, Villejuif, France); Matthieu Carton, Diane Cyr, Annie Schmaus (Inserm Epidemiologic Cohorts Unit-UMS 011 INSERM-UVSQ, Villejuif, France); Joëlle Févotte (University Lyon 1, UMRESTTE, Lyon, France); Corinne Pilorget (French Public Health Agency, Department of Occupational Health, Saint Maurice, France); Gwenn Menvielle (Sorbonne Universités, UPMC Univ Paris 06, INSERM, IPLESP UMRS 1136, Paris, France); Danièle Luce (INSERM U 1085-IRSET, Pointe-à-Pitre, France).

\section{Contributors:}

$\mathrm{DL}$ and $\mathrm{CB}$ designed the current study, conducted the analyses and drafted the manuscript; MM, AA, JD, LR and GM contributed to the statistical analysis and interpretation of the results. JF was involved in exposure assessment. AVG contributed to data collection and quality control. DL and IS are the principal investigators of the ICARE study, conceived this study and coordinated the original collection of the data. All the authors critically reviewed and revised the manuscript, and gave their approval for its final version.

\section{Competing interest}

The authors declare no conflict of interest.

Patient consent: obtained

Ethics approval: The International review board of the French National Institute of health and Medical Research (IRB-INSERM, n 01-036) and by the French Data Protection Authority (CNIL n 90120).

Provenance and peer review: Not commissioned; externally peer reviewed.

\section{Funding}

The ICARE study was funded by the French National Research Agency (ANR); French National Cancer Institute (INCA); French Agency for Food, Environmental and Occupational Health and Safety (ANSES); French Institute for Public Health Surveillance (InVS); Fondation pour la Recherche Médicale (FRM); Fondation de France; Association pour la Recherche sur le Cancer (ARC); Ministry of Labour (Direction Générale du Travail); Ministry of Health (Direction Générale de la Santé). 


\section{References}

1 IARC Working Group on the Evaluation of Carcinogenic Risks to Humans, International Agency for Research on Cancer. Welding, molybdenum trioxide, and indium tin oxide. 2018. http://publications.iarc.fr/569 (accessed 9 Jun 2019).

2 Antonini JM. Health effects of welding. Crit Rev Toxicol 2003;33:61-103. doi:10.1080/713611032

3 Sferlazza SJ, Beckett WS. The respiratory health of welders. Am Rev Respir Dis 1991;143:1134-48. doi:10.1164/ajrccm/143.5_Pt_1.1134

4 Cogliano VJ, Baan R, Straif K, et al. Preventable exposures associated with human cancers. J Natl Cancer Inst 2011;103:1827-39. doi:10.1093/jnci/djr483

5 Gustavsson $\mathrm{P}$, Jakobsson $\mathrm{R}$, Johansson $\mathrm{H}$, et al. Occupational exposures and squamous cell carcinoma of the oral cavity, pharynx, larynx, and oesophagus: a casecontrol study in Sweden. Occup Environ Med 1998;55:393-400.

6 Shangina O. Occupational Exposure and Laryngeal and Hypopharyngeal Cancer Risk in Central and Eastern Europe. Am J Epidemiol 2006;164:367-75. doi:10.1093/aje/kwj208

7 Olsen J, Sabroe S, Lajer M. Welding and cancer of the larynx: a case-control study. Eur J Cancer Clin Oncol 1984;20:639-43.

8 Schildt EB, Eriksson M, Hardell L, et al. Occupational exposures as risk factors for oral cancer evaluated in a Swedish case-control study. 1998.

9 Brown LM, Mason TJ, Pickle LW, et al. Occupational risk factors for laryngeal cancer on the Texas Gulf Coast. Cancer Res 1988;48:1960-4.

10 Merletti F, Boffetta P, Ferro G, et al. Occupation and cancer of the oral cavity or oropharynx in Turin, Italy. Scand J Work Environ Health 1991;17:248-54.

11 Goldberg P, Leclerc A, Luce D, et al. Laryngeal and hypopharyngeal cancer and occupation: results of a case control-study. Occup Environ Med 1997;54:477-82. doi:10.1136/oem.54.7.477

12 Khetan P, Boffetta P, Luce D, et al. Occupations and the Risk of Head and Neck Cancer: A Pooled Analysis of the International Head and Neck Cancer Epidemiology (INHANCE) Consortium. J Occup Environ Med 2019;61:397-404. doi:10.1097/JOM.0000000000001563

13 Huebner WW, Schoenberg JB, Kelsey JL, et al. Oral and pharyngeal cancer and occupation: a case-control study. Epidemiol Camb Mass 1992;3:300-9.

14 Vaughan TL. Occupation and squamous cell cancers of the pharynx and sinonasal cavity. Am J Ind Med 1989;16:493-510.

15 Ahrens W, Jöckel KH, Patzak W, et al. Alcohol, smoking, and occupational factors in cancer of the larynx: a case-control study. Am J Ind Med 1991;20:477-93.

16 Wortley $\mathrm{P}$, Vaughan TL, Davis S, et al. A case-control study of occupational risk factors for laryngeal cancer. Br J Ind Med 1992;49:837-44. doi:10.1136/oem.49.12.837 
17 De Stefani E, Boffetta $\mathrm{P}$, Oreggia $\mathrm{F}$, et al. Occupation and the risk of laryngeal cancer in Uruguay. Am J Ind Med 1998;33:537-42.

18 Elci OC, Dosemeci M, Blair A. Occupation and the risk of laryngeal cancer in Turkey. Scand J Work Environ Health $2001 ; 27: 233-9$.

19 Paget-Bailly S, Guida F, Carton M, et al. Occupation and head and neck cancer risk in men: results from the ICARE study, a French population-based case-control study. $J$ Occup Environ Med 2013;55:1065-73.

20 Carton M, Guida F, Paget-Bailly S, et al. Occupation and head and neck cancer in women-Results of the ICARE study. Am J Ind Med 2014;57:1386-97. doi:10.1002/ajim.22394

21 Guha N, Loomis D, Guyton KZ, et al. Carcinogenicity of welding, molybdenum trioxide, and indium tin oxide. Lancet Oncol 2017;18:581-2. doi:10.1016/S1470-2045(17)30255-3

22 ICARE study group, Luce D, Stücker I. Investigation of occupational and environmental causes of respiratory cancers (ICARE): a multicenter, population-based case-control study in France. BMC Public Health 2011;11. doi:10.1186/1471-2458-11-928

23 International Labour Office. International Standard Classification of Occupations (ISCO). 1968.

24 INSEE. Insitut National de la Satistique et des Etudes Economiques. Nomenclature d'activités francaise. 2000.

25 Lacourt A, Leffondre K, Gramond C, et al. Temporal patterns of occupational asbestos exposure and risk of pleural mesothelioma. Eur Respir J 2012;39:1304-12. doi:10.1183/09031936.00005111

26 Steenland K. Ten-year update on mortality among mild-steel welders. Scand J Work Environ Health 2002;28:163-7. doi:10.5271/sjweh.660

27 Simonato L, Fletcher AC, Andersen A, et al. A historical prospective study of European stainless steel, mild steel, and shipyard welders. Br J Ind Med 1991;48:145-54. doi:10.1136/oem.48.3.145

28 Puntoni R, Merlo F, Borsa L, et al. A historical cohort mortality study among shipyard workers in Genoa, Italy. Am J Ind Med 2001;40:363-70.

29 Becker N. Cancer mortality among arc welders exposed to fumes containing chromium and nickel. Results of a third follow-up: 1989-1995. J Occup Environ Med 1999;41:294303. doi:10.1097/00043764-199904000-00012

30 Danielsen TE, Langård S, Andersen A. Incidence of cancer among Norwegian boiler welders. Occup Environ Med 1996;53:231-4. doi:10.1136/oem.53.4.231

31 Moulin JJ, Wild P, Haguenoer JM, et al. A mortality study among mild steel and stainless steel welders. Br J Ind Med 1993;50:234-43. doi:10.1136/oem.50.3.234

32 Merlo F, Costantini M, Doria M. Cause specific mortality among workers exposed to welding fumes and gases: a historical prospective study. J UOEH 1989;11 Suppl:30215. 
33 Baan $\mathrm{R}$, Grosse $\mathrm{Y}$, Straif $\mathrm{K}$, et al. A review of human carcinogens--Part F: chemical agents and related occupations. Lancet Oncol 2009;10:1143-4.

34 Jéhannin-Ligier $K$, Belot A, Guizard A-V, et al. Incidence trends for potentially human papillomavirus-related and -unrelated head and neck cancers in France using populationbased cancer registries data: 1980-2012: Incidence trends for potentially human papillomavirus-related and -unrelated head and neck cancers in France. Int $J$ Cancer 2017;140:2032-9. doi:10.1002/ijc.30631

35 Ligier K, Belot A, Launoy G, et al. Descriptive epidemiology of upper aerodigestive tract cancers in France: Incidence over 1980-2005 and projection to 2010. Oral Oncol 2011;47:302-7. doi:10.1016/j.oraloncology.2011.02.013 


\section{What this paper adds?}

\section{What is already known about this subject?}

- Evidence about the role of welding on head and neck cancer risk is inconclusive

What are the new findings?

- We found that welding increased the risk of laryngeal cancer.

- Long-term welding increases the risk of oral cancer

- Using acid to clean metal before welding was associated with an increased risk of oral and laryngeal cancer.

How might this impact on policy or clinical practice in the foreseeable future?

- If replicated in future studies, these findings can impact on work practices and workplace preventive policies, as well as on compensation of occupational diseases. 